\title{
EFEITO DOS SUBSTRATOS ARTIFICIAIS NO ENRAIZAMENTO E NO DESENVOLVIMENTO DE ESTACAS DE MARACUJAZEIRO-AZEDO (Passiflora edulis Sims f. flavicarpa Deg) ${ }^{1}$
}

\author{
JAIME ABRÃO DE OLIVEIRA², NILTON TADEU VILELA JUNQUEIRA ${ }^{3}$ JOSÉ RICARDO PEIXOTO ${ }^{4}$, \\ AILTON VITOR PEREIRA ${ }^{3}$
}

\begin{abstract}
RESUMO - Os ensaios foram instalados em casa de vegetação na Embrapa Cerrados, Planaltina-DF, em agosto de 1999. Nos primeiros 30 dias, estacas da cultivar MSC (Marília Seleção Cerrados) foram mantidas sob nebulização com duas regas diárias. Avaliaram-se os seguintes parâmetros: percentagens de estacas brotadas, enraizadas, com fungos, peso de matéria fresca e seca da parte aérea e das raízes, aos 90 dias após o plantio. O estudo foi composto de dois experimentos. No primeiro, utilizaram-se estacas coletadas em agosto de 1999, e oito tipos de substratos. O Plantmax Florestal Estaca ${ }^{\circledR}$ proporcionou maior brotação e enraizamento, e ainda menor incidência de estacas contaminadas por Colletotrichum gloeosporioides, comparativamente ao substrato à base de Plantmax Hortaliças. ${ }^{\circledR}$ O aditivo Nutriplanta ${ }$, quando combinado com o fertilizante Osmocote $\AA$, no substrato à base de Plantmax Florestal Estaca ${ }^{\circledR}$, proporcionou maior brotação e enraizamento e também menor incidência de estacas contaminadas com C. gloeosporioides. No segundo ensaio, utilizaram-se estacas do híbrido RC1 ((F1: Marília x Roxo Australiano) x Marília), coletadas em agosto de 2000, tratadas com 2.000 ppm de AIB, plantadas em bandejas de poliestireno expandido com doze tipos de substratos. Para enraizamento das estacas do Híbrido RC1, não houve diferença entre os substratos testados. A adição de um g de Osmocote ${ }^{\circledR}$ por estaca, aos 30 dias após o plantio no substrato Plantmax Florestal Estaca ${ }^{\circledR}$, proporcionou o melhor desenvolvimento da parte aérea das estacas do Híbrido RC1.
\end{abstract}

Termos de indexação: 1. Propagação assexuada 2. estaquia 3. Mudas 4. bandejas de poliestireno

\section{EFFECT OF THE ARTIFICIAL SUBSTRATES ON THE ROOTING AND BUDDING OF PASSION FRUIT (Passiflora edulis Sims f. flavicarpa Deg.) CUTTINGS}

\begin{abstract}
The experiments were carried out (August to November of 1999 and 200) under greenhouse conditions in Embrapa Cerrados, Planaltina-DF. In the first assay, passion fruits (Cv. Marília-MSC) cuttings containing two internodes were immersed in IBA (indolbutiric acid) solution at 2000 ppm for 10 seconds and planted in expanded polystyrene trays, with 72 units containing eight organic substrates. The evaluation was made 90 days after planting, by determining the percentage of rooted and budded cuttings and the incidence (\% of died cuttings) of Colletotrichum gloeosporioides. The Plantmax Florestal Estaca ${ }^{\circledR}$ exhibited higher level of budding and rooting and lower incidence of $C$. gloeosporioides compared to the substrate Plantmax Hortaliças ${ }^{\circledR}$. The Nutriplanta ${ }^{\circledR}$ combined with Osmocote ${ }^{\circledR}$ was more efficient than the Plantmax Florestal Estaca ${ }^{\circledR}$. In the second assay, the cuttings of hybrid RC1 ((F1: Marilia X Roxo Australiano) x Marília) were collected in August 2000 and treated with 2000 ppm of IBA. The organic substrates used were twelve. The results indicated that the rooting level of RC1 cutting was similar for all substrates. The addition of $1 \mathrm{~g}$ of Osinocote per cutting, 30 days after they were planted in substrate plantmax florestal estaca, prorrided the better development to aerial portion for the RC1 hybrid.
\end{abstract}

Index terms: 1 . Asexual propagation 2. polystyrene trays 3. Seedling

\section{INTRODUÇÃO}

As vantagens da muda obtida por estaquia ou por outro processo assexual consistem no fato de se obter plantas com estabilidade genética garantida, o que implicará a formação de pomares mais uniformes, mais produtivos e frutos mais homogêneos. Por ser o maracujazeiro uma espécie alógama, as cultivares multiplicadas por sementes dão origem a plantas e frutos desuniformes e degeneram-se rapidamente devido à endogamia. Há grande carência de estudos em relação a substratos na formação de mudas de maracujazeiro por estaquia.
Borges et al. (1995) relatam que o substrato consiste num fator importante para a formação de mudas de boa qualidade. Dessa forma, objetivando avaliar substratos para produção de mudas de maracujazeiro por estaquia, foram conduzidos dois experimentos onde se testaram diferentes substratos.

\section{MATERIAL E MÉTODOS}

Para este estudo, foram montados dois ensaios em casa de vegetação, em dois ambientes, na Embrapa Cerrados,

1 (Trabalho 093/2001). Recebido: 30/04/2001. Aceito para publicação: 08/02/2002.

2 Mestrando em Fitotecnia na UnB/FAV, CP 04508 CEP.: 70910-970 Brasília -DF. jabraoli@bol.com.br

3 Pesquisadores da EMBRPA Cerrados CP 08223, CEP.: 73301-970 Planaltina-DF. junqueir@cpac.embrapa.br

4 Professor da UnB/FAV CP 04508 CEP.: 70910-970 Brasília -DF. peixoto@unb.br 
Planaltina-DF. No primeiro, a temperatura foi controlada por meio de um termostato, que acionava o sistema de ventiladores. A umidade foi controlada por um umidostato que acionava o sistema de nebulização intermitente quando a umidade baixava de $70 \%$. Para registrar a variação da temperatura e umidade relativa, instalou-se um termoigrógrafo dentro da casa de vegetação. A umidade relativa oscilou de $70 \%$ a $100 \%$, e a temperatura variou de $16^{\circ} \mathrm{C}$ a $20^{\circ} \mathrm{C}$ à noite e de $20^{\circ} \mathrm{C} \mathrm{a} 28^{\circ} \mathrm{C}$ ao dia. Após 30 dias, as bandejas com as estacas foram transferidas para um segundo ambiente, com ventilação e duas regas diárias de $4 \mathrm{~L} / \mathrm{m}^{2}$ sendo uma às 12 horas e a outra às 15 horas.

Os substratos-base utilizados nos dois ensaios foram: 1) Plantmax Hortaliças ${ }^{\circledR}$, um substrato comercial composto de casca de pinus e turfa enriquecidas e processadas, vermiculita, umidade de $50 \%$ a $55 \%$, densidade de $450 \pm 5 \mathrm{~kg} / \mathrm{m}^{3}, \mathrm{pH}$ de 5,5-6,2 e condutividade elétrica de 1,8-2,5 mS/cm. 2) Plantmax Florestal Estaca $^{\circledR}$ apropriado para enraizamento de estacas e composto de casca de pinus processada e enriquecida, vermiculita e perlita, umidade $50-55 \%$, densidade de $420 \pm 5 \mathrm{~kg} / \mathrm{m}^{3}, \mathrm{pH}$ de $5,5-6,2$ e condutividade elétrica de $1,8-2,0 \mathrm{mS} / \mathrm{cm}$.

Como complemento, foram utilizados os fertilizantes Osmocote ${ }^{\circledR}$ e Nutriplanta ${ }^{\circledR}$. O Osmocote ${ }^{\circledR}$ é um fertilizante de liberação lenta, à base de 14-14-14, de N- $\mathrm{P}_{2} \mathrm{O}_{5}-\mathrm{K}_{2} \mathrm{O}$, onde os nutrientes são liberados pela ação do binômio umidade e temperatura, por um período de três meses à temperatura de $21^{\circ} \mathrm{C}$, sendo que o nitrogênio apresenta-se com 50\% na forma nítrica e $50 \%$ na amoniacal. O Nutriplanta ${ }^{\circledR}$ é um aditivo composto de materiais orgânicos fermentado por bactérias, cuja análise demonstrou os seguintes resultados: $\mathrm{pH}$ em água $6,5, \mathrm{pH}$ em $\mathrm{CaCl}_{2}$ de 6,5 , umidade a $65^{\circ} \mathrm{C}$ de $29,2 \%$, umidade total a $105^{\circ} \mathrm{C}$ de $31,5 \%$, matéria orgânica total de $47 \%$, carbono total de $27,2 \%$, resíduo mineral total de $21,5 \%$, resíduo mineral solúvel $18,5 \%$, resíduo mineral insolúvel de $3,0 \%$, nitrogênio total de $20,6 \%$, relação $\mathrm{C} / \mathrm{N}$ de 13,2 , fósforo de $14,2 \mathrm{~g} / \mathrm{kg}$, potássio de $21,9 \mathrm{~g} / \mathrm{kg}$, cálcio de $84,3 \mathrm{~g} /$ $\mathrm{kg}$, magnésio de $5,7 \mathrm{~g} / \mathrm{kg}$, enxofre de $3,6 \mathrm{~g} / \mathrm{kg}$; boro de $31 \mathrm{mg} / \mathrm{kg}$, zinco de $329 \mathrm{mg} / \mathrm{kg}$, ferro de $2897 \mathrm{mg} / \mathrm{kg}$, manganês $577 \mathrm{mg} / \mathrm{kg}$ e também cobre $55 \mathrm{mg} / \mathrm{kg}$, analisados pela metodologia de Kiehl (1985). Dessa forma, os tratamentos utilizados no primeiro ensaio foram: $\mathrm{EON}=$ Plantmax Florestal Estaca ${ }^{\circledR}+350 \mathrm{~g}$ de Osmocote $^{\circledR}$ em 55 L substrato $+10 \%$ do volume de Nutriplanta ${ }^{\circledR}$; $\mathrm{E}=$ Plantmax Florestal Estaca $^{\circledR} ; \mathrm{EN}=$ Plantmax Florestal Estaca $^{\circledR}$ $+10 \%$ do volume de Nutriplanta ${ }^{\circledR} ; \mathrm{EO}=$ Plantmax Florestal Esta$\mathrm{ca}^{\circledR}+350 \mathrm{~g}$ de Osmocote ${ }^{\circledR}$ em 55 L substrato; PX = Plantmax Hortaliças $^{\circledR}$ (testemunha); PXN = Plantmax Hortaliças ${ }^{\circledR}+10 \%$ do volume de Nutriplanta ${ }^{\circledR} ;$ PXON $=$ Plantmax Hortaliças ${ }^{\circledR}+350 \mathrm{~g}$ de Osmocote ${ }^{\circledR}$ em 55 L substrato $+10 \%$ do volume de Nutriplanta $^{\circledR} ; \mathrm{PXO}=$ Plantmax Hortaliças $^{\circledR}+350 \mathrm{~g} \mathrm{de} \mathrm{Osmocote}^{\circledR}$ por $55 \mathrm{~L}$ substrato.

O primeiro ensaio foi conduzido de agosto a novembro de 1999, utilizando estacas da cultivar Marília Seleção Cerrados, coletadas em plantios da Embrapa Cerrados, na estação seca, em plantas com dois anos, na posição mediana do ramo (região de folhas verdes, desprezando somente a parte apical do ramo), contendo de cinco a oito milímetros de espessura, seguindo as recomendações da Comissão Estadual de Sementes e Mudas (CESM, 1999).

As estacas foram preparadas e padronizadas com dois nós, sem as folhas e, antes de serem mergulhadas por 10 segundos em uma solução de AIB (ácido indolbutírico), tiveram suas extremidades basais seccionadas em $0,5 \mathrm{~cm}$ para eliminar o tecido oxidado. O plantio foi efetuado em bandeja de poliestireno expandido (Isopor ${ }^{\circledR}$ ) de 72 células, contendo os substratos (tratamentos). As estacas tiveram suas bases introduzidas no substrato à profundidade de três $\mathrm{cm}$. Em seguida, efetuou-se a compressão manual do substrato para a retirada do ar.

O ensaio foi instalado em blocos casualizados, com parcela de 12 plantas e seis repetições. Para preparar a solução de AIB, foram dissolvidos dois gramas de AIB em $50 \mathrm{ml}$ de álcool hidratado $\left(96^{\circ} \mathrm{GL}\right)$ e depois diluído em $950 \mathrm{ml}$ de água, formando uma solução de 2.000 ppm, conforme resultados de Santana et al. (2001).

O segundo ensaio foi conduzido no período de agosto a novembro de 2000, utilizando-se de estacas do Híbrido RC1 ((F1: Marília x Roxo Australiano) x Marília), coletadas em um plantio comercial com idade de um ano, seguindo os mesmos padrões anteriores.

Neste ensaio, utilizou-se um delineamento em blocos casualizados, com três repetições e parcelas de seis plantas, sendo acrescido do fertilizante Plantafol ${ }^{\circledR}$ na formulação $20-20-20$, de N$\mathrm{P}_{2} \mathrm{O}_{5}-\mathrm{K}_{2} \mathrm{O}$, mais $0,05 \%$ de boro e $0,2 \%$ de ferro quelatizado com EDTA.

Os tratamentos do segundo ensaio foram: $\mathrm{PXOM}=$ Plantmax Hortaliças ${ }^{\circledR}+350$ g de Osmocote ${ }^{\circledR}$ misturado em $55 \mathrm{~L}$ substrato; PX = Plantmax Hortaliças ${ }^{\circledR}$ (testemunha); EWA = Plantmax Florestal Estaca ${ }^{\circledR}+1$ g de Plantafol $^{\circledR}$ por L de água, na formulação 20-20-20 de N- $\mathrm{P}_{2} \mathrm{O}_{5}-\mathrm{K}_{2} \mathrm{O}$, via fertirrigação de 15 em 15 dias, $\mathrm{PXON}=$ Plantmax Hortaliças $^{\circledR}+350 \mathrm{~g}$ de Osmocote ${ }^{\circledR}$ misturado em $55 \mathrm{~L}$ substrato $+10 \%$ do volume de Nutriplanta ${ }^{\circledR} ;$ PX10 $=$ Plantmax Hortaliças $^{\circledR}+490 \mathrm{~g}$ da formulação de 10-10-10 de N$\mathrm{P}_{2} \mathrm{O}-\mathrm{K}_{2} \mathrm{O}$ em $55 \mathrm{~L}$ de substrato; PXWA = Plantmax Hortaliças ${ }^{\circledR}+$ $1 \mathrm{~g}$ de Plantafol ${ }^{\circledR}$ por L de água, na formulação $20-20-20$ de N$\mathrm{P}_{2} \mathrm{O}_{5}-\mathrm{K}_{2} \mathrm{O}$, via fertirrigacão de 15 em 15 dias; E10 = Plantmax Florestal Estaca ${ }^{\circledR}+490 \mathrm{~g}$ da formulação de 10-10-10 de $\mathrm{N}-\mathrm{P}_{2} \mathrm{O}_{5}-\mathrm{K}_{2} \mathrm{O}$ em 55 L de substrato; EOM = Plantmax Florestal Estaca ${ }^{\circledR}+350 \mathrm{~g}$ de Osmocote ${ }^{\circledR}$ misturado em 55 L substrato; EON = Plantmax Florestal Estaca ${ }^{\circledR}+350$ g de Osmocote ${ }^{\circledR}$ misturado em $55 \mathrm{~L}$ substrato $+10 \%$ do volume de Nutriplanta ${ }^{\circledR} ;$ PXOS $=$ Plantmax Hortaliças $^{\circledR}+1 \mathrm{~g}$ de Osmocote ${ }^{\circledR}$ superficial por célula da bandeja 30 dias após o plantio; E = Plantmax Florestal Estaca ${ }^{\circledR} ; \mathrm{EOS}=$ Plantmax Florestal Estaca ${ }^{\circledR}+1$ g de Osmocote ${ }^{\circledR}$ superficial por $^{\circ}$ célula da bandeja.

Os seguintes parâmetros foram avaliados: percentagem de estacas brotadas, enraizadas e com fungos; peso de matéria fresca da parte aérea e das raízes e peso de matéria seca da parte aérea e das raízes, aos 90 dias após o plantio, desconsiderandose o peso das estacas.

\section{RESULTADOS E DISCUSSÕES}

Os dados relativos às análises das variáveis estudadas estão apresentados nas Tabelas 1 e 2. Verificaram-se diferenças significativas para percentagem de estacas brotadas, enraizadas e com antracnose, não havendo diferença para os demais parâmetros.

O substrato que mais se destacou na percentagem de estacas brotadas e enraizadas, foi EON (Tabela 1), apesar de não diferir estatisticamente dos substratos E, EN, EO e PX. O pior 
desempenho foi apresentado pelo substrato PXO, porém esse substrato apresentou maior índice de estacas mortas pelo fungo Colletotrichum gloeosporioides que causa necrose dos tecidos e morte das estacas. Na Figura 1, podem ser observados os sinais desse fungo que são caracterizados pela presença de acérvulos de $C$. gloeosporioides e peritécios (pontuações escuras) de Glomerella cingulata, sua fase perfeita ou sexuada.

Os substratos EN, E e EON induziram melhores resultados, com média de estacas infectadas em torno de $20 \%$, diferindo do PXON e PXO. Graça (1990) também observou o crescimento de C. gloeosporioides e bactérias a ponto de comprometer o enraizamento das estacas de maracujazeiro-azedo.

Todos os substratos à base de Plantmax Hortaliças ${ }^{\circledR}$ induziram menores percentagens de estacas enraizadas e brotadas, e maior percentagem de estacas mortas por $C$. gloeosporioides.

Para o segundo ensaio, não houve diferenças significativas em relação ao percentual de estacas brotadas e enraizadas. No entanto, o PXOM apresentou melhor desempenho em relação a estacas brotadas e o substrato EWA para as estacas enraizadas. As piores médias para estas duas características e também maior quantidade de estacas infectadas por $C$. gloeosporioides foram obtidas no substrato EOS (Tabela 2).

Também não houve diferenças significativas para os pesos de matéria fresca e seca das raízes, onde o EOS apresentou melhor desempenho para essas características. O substrato $\mathrm{E}$ puro, proporcionou o pior desempenho, com variação de $3,3 \mathrm{~g} \mathrm{e}$ $0,34 \mathrm{~g}$ para as maiores médias e de $1,1 \mathrm{~g}$ e $0,09 \mathrm{~g}$, respectivamen- te, para as duas variáveis analisadas. Houve diferença quando se compararam os substratos em relação aos pesos de matéria fresca e seca da parte aérea, como se pode observar na Tabela 2. O substrato EOS, embora não se destacasse nas características anteriores, foi o que proporcionou o melhor desenvolvimento da parte aérea das estacas brotadas. Observou-se que mudas oriundas de estaquia contendo acima de quatro g de matéria fresca das raízes apresentaram excelente nível de enraizamento, tendo também parte aérea em igual proporção.

Quanto ao enraizamento de maracujazeiro-azedo, Ruggiero (1987), trabalhando em câmara de nebulização com estacas com um nó e meia-folha, um nó e uma folha, dois nós e duas meias-folhas, dois nós e duas folhas, três nós e três meiasfolhas e estacas com três nós e três folhas, obteve, respectivamente, $70,6 \%, 58,6 \%, 80,0 \%, 57,3 \%, 56 \%$ e $33 \%$ de estacas enraizadas. Almeida et al.(1991), trabalhando com estacas sem folhas, estaca com meia-folha e estaca com folha inteira retirada de pomar com um ano de idade e usando areia grossa lavada como substrato, obtiveram, respectivamente, $41,4 \%, 74,3 \%$ e 88 , $9 \%$ de enraizamento. Estes autores verificaram que a presença da folha inteira ou em parte favorece o enraizamento de estacas. Matsumoto \& São José (1989), testando substratos à base de carvão, esterco curtido de curral e areia grossa, obtiveram percentuais de estacas enraizadas superiores a 80\%. São José (1991) relata percentuais de enraizamento de estacas acima de $90 \%$, sem o uso de fitormônios vegetais, quando as estacas são mantidas em leito de areia grossa lavada, dentro de estufim de plástico com insolação diária de $50 \%$ e sob regas diárias. Compa-

TABELA 1- Percentagem de estacas brotadas, enraizadas e com fungo C. gloesosporioides e pesos de matéria fresca e seca de parte aérea e das raízes das estacas do primeiro ensaio de maracujazeiro-azedo, em Planaltina-DF, 1999.

\begin{tabular}{|c|c|c|c|c|c|c|c|c|}
\hline \multirow{2}{*}{$\begin{array}{l}\text { Substrato } \\
\text { (Trat.) }\end{array}$} & \multicolumn{3}{|c|}{ Percentagem de estacas (\%) } & \multicolumn{2}{|c|}{ Parte aérea (PA) } & \multicolumn{2}{|c|}{ Sistema radicular (SR) } & \multirow{2}{*}{$\begin{array}{c}\text { Relação } \\
\text { PA / SR } \\
(\text { peso } \\
\text { fresco) }\end{array}$} \\
\hline & Brotadas & Enraizadas & $\begin{array}{c}\text { Com } \\
\text { fungo }\end{array}$ & $\begin{array}{c}\text { Peso fresco } \\
(\mathrm{g})\end{array}$ & $\begin{array}{c}\text { Peso seco } \\
(\mathrm{g})\end{array}$ & $\begin{array}{c}\text { Peso fresco } \\
(\mathrm{g})\end{array}$ & $\begin{array}{c}\text { Peso seco } \\
(\mathrm{g})\end{array}$ & \\
\hline $\mathrm{EON}$ & 57,0 a & 74,0 a & $20,8 \mathrm{~b}$ & $2.13 \mathrm{a}$ & $0,170 \mathrm{a}$ & $1,54 \mathrm{a}$ & 0,473 a & 1,38 \\
\hline $\mathrm{E}$ & $45,7 \mathrm{ab}$ & 57,8 ab & $19,7 \quad b$ & $1,14 \mathrm{a}$ & 0,128 a & 0,96 a & 0,248 a & 0,90 \\
\hline $\mathrm{EN}$ & 38,9 abc & $71,2 \mathrm{ab}$ & $18,2 \quad b$ & $1,84 \mathrm{a}$ & 0,088 a & $0,54 \mathrm{a}$ & $0,216 \mathrm{a}$ & 3,40 \\
\hline EO & $34,1 \mathrm{abcd}$ & $54,2 \mathrm{abc}$ & $41,4 \mathrm{ab}$ & $1,72 \mathrm{a}$ & $0,114 \mathrm{a}$ & 0,94 a & 0,385 a & 1,82 \\
\hline $\mathrm{PX}$ & $33,1 \mathrm{abcd}$ & $47,1 \quad \mathrm{~cd}$ & $45,6 \mathrm{ab}$ & $1,34 \mathrm{a}$ & 0,152 a & $0,53 \mathrm{a}$ & $0,303 \mathrm{a}$ & 2,52 \\
\hline $\mathrm{PXN}$ & $25,0 \quad b c d$ & 43,9 & $45,6 \mathrm{ab}$ & $1,43 \mathrm{a}$ & $0,106 \mathrm{a}$ & $0,81 \mathrm{a}$ & $0,280 \mathrm{a}$ & 1,76 \\
\hline $\mathrm{PXON}$ & $14,5 \quad \mathrm{~cd}$ & 25,7 & $60,2 \mathrm{a}$ & $2,00 \mathrm{a}$ & $0,175 \mathrm{a}$ & $1,12 \mathrm{a}$ & $0,443 \mathrm{a}$ & 1,78 \\
\hline $\mathrm{PXO}$ & 12,5 & 20,7 & $68,0 \mathrm{a}$ & $1,97 \mathrm{a}$ & $0,145 \mathrm{a}$ & $1,35 \mathrm{a}$ & $0,441 \mathrm{a}$ & 1,45 \\
\hline
\end{tabular}

Média na mesma coluna, seguida pela mesma letra, não difere pelo teste de Tukey, ao nível de $5 \%$ de probabilidade.

TABELA 2 - Percentagem de estacas brotadas, enraizadas e com fungos e pesos de matéria fresca e seca de parte aérea e das raízes das estacas do segundo ensaio de maracujazeiro-azedo, em Planaltina-DF, 2000

\begin{tabular}{|c|c|c|c|c|c|c|c|c|}
\hline \multirow{2}{*}{$\begin{array}{l}\text { Substrato } \\
\text { (Trat.). }\end{array}$} & \multicolumn{3}{|c|}{ (Percentagem de estacas (\%) } & \multicolumn{2}{|c|}{ Parte aérea (PA) } & \multicolumn{2}{|c|}{ Sistema radicular (SR) } & \multirow{2}{*}{$\begin{array}{c}\text { Relação } \\
\text { PA / SR } \\
\text { (peso } \\
\text { fresco) }\end{array}$} \\
\hline & Brotadas & Enraizadas & $\begin{array}{c}\text { Com } \\
\text { fungos }\end{array}$ & Peso fresco (g) & Peso seco $(g)$ & Peso fresco $(g)$ & $\begin{array}{c}\text { Peso seco } \\
(\mathrm{g})\end{array}$ & \\
\hline PXOM & $46,2 \mathrm{a}$ & $65 \mathrm{a}$ & $34 \mathrm{ab}$ & $2,15 \mathrm{~b}$ & $0,49 \mathrm{~b}$ & $2,10 \mathrm{a}$ & $0,24 \mathrm{a}$ & 1.02 \\
\hline $\mathrm{PX}$ & 43,9 a & $63 \mathrm{a}$ & $40 \mathrm{ab}$ & $1,81 \mathrm{~b}$ & $0,33 \quad \mathrm{~b}$ & $1,51 \mathrm{a}$ & $0,14 \mathrm{a}$ & 1.19 \\
\hline E W A & 43,7 a & $75 \mathrm{a}$ & $24 \mathrm{ab}$ & $1,49 \mathrm{~b}$ & $0,32 \quad b$ & $1,97 \mathrm{a}$ & 0,22 a & 0.75 \\
\hline $\mathrm{PXON}$ & $41,7 \mathrm{a}$ & $70 \mathrm{a}$ & $18 \mathrm{a}$ & $2,54 \quad b$ & 0,38 & $1,41 \mathrm{a}$ & $0,14 \mathrm{a}$ & 1.80 \\
\hline PX 10 & $41,5 \mathrm{a}$ & $57 \mathrm{a}$ & $42 \mathrm{ab}$ & $2,74 \quad b$ & $0,53 \quad \mathrm{~b}$ & $2,15 \mathrm{a}$ & $0,25 \mathrm{a}$ & 1.27 \\
\hline $\mathrm{PX} \mathrm{W} \mathrm{A}$ & $40,1 \mathrm{a}$ & $63 \mathrm{a}$ & $36 \mathrm{ab}$ & $2,64 \mathrm{~b}$ & 0,38 & $1,72 \mathrm{a}$ & $0,23 \mathrm{a}$ & 1.53 \\
\hline E 10 & $39,5 \mathrm{a}$ & $59 \mathrm{a}$ & $40 \mathrm{ab}$ & $2,12 \quad b$ & 0,32 & $1,55 \mathrm{a}$ & $0,11 \mathrm{a}$ & 1.36 \\
\hline EOM & $38,7 \mathrm{a}$ & $61 \mathrm{a}$ & $40 \mathrm{ab}$ & $1,72 \mathrm{~b}$ & 0,32 & $1,27 \mathrm{a}$ & $0,14 \mathrm{a}$ & 1.35 \\
\hline EON & $37,6 \mathrm{a}$ & $57 \mathrm{a}$ & $42 \mathrm{ab}$ & $1,69 \mathrm{~b}$ & 0,31 & $2,35 \mathrm{a}$ & $0,26 \mathrm{a}$ & 0.71 \\
\hline $\mathrm{PXOS}$ & 28,9 a & $42 \mathrm{a}$ & $57 \mathrm{ab}$ & $2,31 \quad b$ & $0,52 \quad b$ & $1,69 \mathrm{a}$ & $0,17 \mathrm{a}$ & 1.36 \\
\hline $\mathrm{E}$ & 25,8 a & $61 \mathrm{a}$ & $38 \mathrm{ab}$ & $0,64 \quad b$ & $0,14 \quad b$ & $1,10 \mathrm{a}$ & 0,08 a & 0.58 \\
\hline EOS & $24,7 \mathrm{a}$ & $31 \mathrm{a}$ & $59 \quad \mathrm{~b}$ & $9,38 \mathrm{a}$ & $2,18 \mathrm{a}$ & $3,34 \mathrm{a}$ & $0,34 \mathrm{a}$ & 2.81 \\
\hline
\end{tabular}

Média na mesma coluna, seguida pela mesma letra, não difere pelo teste de Tukey, ao nível de $5 \%$ de probabilidade. 
rando esses resultados com os obtidos no presente trabalho (Tabelas 1 e 2), verificam-se índices de enraizamento similares obtidos em alguns substratos como EON, EN, EWA, PXON e outros. No entanto, nenhum dos autores relatou o percentual de estacas brotadas, parâmetro este que deve ser considerado.

Em ambos os experimentos, além da alta incidência do fungo $C$. gloeosporioides (Tabelas 1 e 2), foram observadas larvas do microdíptero Fungus gnat atacando a base das estacas e causando-lhes a morte. Dessa forma, não há dúvidas de que esses organismos tenham afetado negativamente o resultado final dos experimentos, uma vez que não foram adotadas medidas de controle.

\section{CONCLUSÕES}

1. Uso de substrato à base de Plantmax Florestal Estaca ${ }^{\circledR}$ proporcionou maior brotação e enraizamento e menor incidência de Colletotrichum gloeosporioides nas estacas da Cv. MSC.

2. O fertilizante Osmocote, ${ }^{\circledR}$ com o Aditivo Nutriplanta ${ }^{\circledR}$ no substrato à base Plantmax Florestal Estaca ${ }^{\circledR}$, proporcionou maior brotação, maior enraizamento e menor incidência de C. gloeosporioides nas estacas da Cv. MSC.

3. Não houve diferenças significativas no enraizamento das estacas do Híbrido RC1 ((F1: Marília x Roxo Australiano) x Marília) em relação aos substratos testados.

4. A adição de um grama de Osmocote ${ }^{\circledR}$ por estaca no substrato Plantmax Florestal Estaca ${ }^{\circledR}$ aumentou a porcentagem de estacas brotadas.

\section{REFERÊNCIAS BIBLIOGRÁFICAS}

ALMEIDA, L. P.; BOARETTO, M. A. C.; SANTANA, R. G.; NASCIMENTO, G. M.; SOUSA, P. J. S; SÃO JOSÉ, A. R. Estaquia e comportamento de maracujazeiro (Passiflora edulis SIMS flavicarpa DEG.) propagados por via sexual e vegetativa. Revista Brasileira de Fruticultura, Cruz das Almas, v.13, n.1, p.153-
156, out/1991.

BORGES, A.L.; LIMA, A.A. de; CALDAS, R.C. Adubação orgânica e química na formação de mudas de maracujazeiros. Revista Brasileira de Fruticultura, Cruz das Almas, v. 17, n. 2, p. 17-22. 1995.

COMISSÃO ESTADUAL DE SEMENTES E MUDAS DO DISTRITO FEDERAL. Normas e padrões técnicos para produção e comercialização de mudas no Distrito Federal. Brasília, 102p. 1999.

GRAÇA. J. Estudo sobre a propagação do maracujazeiro (Passiflora edulis SIMS flavicarpa DEG.) através de sementes e estacas. 1990. 92f. Dissertação (mestrado) - Faculdade de Ciências Agrárias e Veterinárias, Universidade Estadual Paulista, Jaboticabal, 1990.

KIEHL, E.J. Fertilizantes orgânicos. Piracicaba: Agronômica Ceres, 1985. 492p.

MATSUMOTO, S. N.; SÃO JOSÉ, A. R. Influência de diferentes substratos no enraizamento de maracujazeiro (Passiflora edulis Sims flavicarpa DEG.). In: CONGRESSO BRASILEIRODE FRUTICULTURA, 10. 1989, Fortaleza. Resumos... Fortaleza: SBF, 1989, p.54.

RUGGIERO, C. Maracujá. Ribeirão Preto: Legis Summa, 1987. 250p.

SANTANA, C.B.; JUNQUEIRA, N.T.V.; MANICA, I.; PEREIRA, A.V.; OLIVEIRA, J.A. Produção de mudas de maracujazeiroazedo por estaquia. Brasília: EMBRAPA-Cerrados, 2001. (Comunicado técnico em preparo).

SÃO JOSÉ, A.R. Propagação do maracujazeiro. In: SÃO JOSÉ, A. R.; FERREIRA, F. R.; VAZ, R. L. A cultura do maracujá no Brasil. Jaboticabal: FUNEP/UNESP, 1991. p.25-41. 